\title{
ADDITION OF HYDROXYAPATITE IMPROVES STIFFNESS, INTERCONNECTIVITY AND OSTEOGENIC POTENTIAL OF A HIGHLY POROUS COLLAGEN-BASED SCAFFOLD FOR BONE TISSUE REGENERATION
}

\author{
J.P. Gleeson ${ }^{1,2 *}$, N.A. Plunkett ${ }^{2}$, and F.J. O’Brien ${ }^{1,2}$ \\ ${ }^{1}$ Trinity Centre for Bioengineering, Department of Mechanical and Manufacturing Engineering, Trinity College, \\ Dublin, Ireland \\ ${ }^{2}$ Department of Anatomy, Royal College of Surgeons in Ireland, Dublin, Ireland
}

\begin{abstract}
There is an enduring and unmet need for a bioactive, loadbearing tissue-engineering scaffold, which is biocompatible, biodegradable and capable of facilitating and promoting osteogenesis when implanted in vivo. This study set out to develop a biomimetic scaffold by incorporating osteoinductive hydroxyapatite (HA) particles into a highly porous and extremely biocompatible collagenbased scaffold developed within our laboratory over the last number of years to improve osteogenic performance. Specifically we investigated how the addition of discrete quantities of HA affected scaffold porosity, interconnectivity, mechanical properties, in vitro mineralisation and in vivo bone healing potential. The results show that the addition of HA up to a 200 weight percentage (wt\%) relative to collagen content led to significantly increased scaffold stiffness and pore interconnectivity (approximately 10 fold) while achieving a scaffold porosity of $99 \%$. In addition, this biomimetic collagen-HA scaffold exhibited significantly improved bioactivity, in vitro mineralisation after 28 days in culture, and in vivo healing of a critical-sized bone defect. These findings demonstrate the regenerative potential of these biodegradable scaffolds as viable bone graft substitute materials, comprised only of bone's natural constituent materials, and capable of promoting osteogenesis in vitro and in vivo repair of critical-sized bone defects.
\end{abstract}

Keywords: Collagen, hydroxyapatite, scaffold, bone tissue engineering, bone regeneration.

\author{
*Address for correspondence: \\ J.P. Gleeson \\ Department of Anatomy \\ Royal College of Surgeons in Ireland \\ 123 St. Stephens Green \\ Dublin 2, Ireland
}

Telephone Number: +353(0)1-402-8536

FAX Number: +353(0)1-402-2355

E-mail: johngleeson@rcsi.ie
Introduction

Bone grafts and bone graft substitutes are used in the repair and reconstruction of bone tissue defects throughout the body that can arise as a result of any number injuries to the tissue. Currently, the "gold standard" clinical approach involves the surgical harvesting of autograft tissue, taken from the patient's own body and subsequently reimplanted into the patient's defect site. However, there are significant practical and surgical complications associated with this approach, specifically donor site morbidity, quantity of harvest tissue available (Laurencin et al., 2006; Toolan, 2006; Desai, 2007), quality of geriatric/pathological source tissue (Bridwell et al., 2004) and need for a second surgical procedure (Arrington et al., 1996). Tissue-derived substitutes such as allografts and xenografts offer significant practical advantages over autograft material (e.g. no need for additional surgery, "off the shelf" availability, size of graft material). However, significant drawbacks such as worldwide donor shortage (Greenwald et al., 2001) and associated risk of disease transmission (Mroz et al., 2008) ensure that allografting is insufficient as a viable long-term approach to bone autografting.

Focus has recently switched towards the use of alternative approaches to attempt to promote and facilitate the body's own bone tissue healing ability. These approaches have included stem cell technology, tissue engineering and the development of cell-free scaffolds to act as bone graft substitutes. Synthetically-derived bone graft substitutes, such as ceramic (hydroxyapatite, $\beta$-TCP) or polymeric-based (poly-L-lactide, PLLA; poly(lacticco-glycolic) acid, PLGA) scaffolds have a number of advantages such as high mechanical strength, osteoinductivity and biodegradability. Unfortunately these current solutions have a number of associated disadvantages (such as low porosity, toxic degradation by-products and long term mechanical integrity issues (Athanasiou et al., 1998; Revell et al., 1998; Spain et al., 1998; Bohner, 2000; Bohner et al., 2000; Hunziker et al., 2002; Woodfield et al., 2002) and have enjoyed limited clinical success (Ratcliffe, 2008). These strategies prioritise mechanically-competent scaffolds at the expense of biocompatibility and biological performance. This has resulted in an enduring and unmet need for a bioactive, load-bearing scaffold, capable of promoting osteogenesis in vivo (Barrere et al., 2008).

Recent advances in composite biomaterials have led to a paradigm shift towards biomimetic tissue engineering scaffolds for use in the regeneration of bone tissue defects. Biomimetics, both in terms of composition and fabrication, 
process may provide a compromise between the competing mechanical and the biological prerequisites needed to rapidly promote healing of bone tissue defects. Given bone's native composition of predominantly type I collagen and hydroxyapatite, these materials are an obvious choice as the basis for a composite biomaterial capable of supporting and promoting the bone regenerative process (Wahl and Czernuszka, 2006). Recent studies have shown that improvements in the interaction between osteoblasts and PLLA scaffolds can be improved by the application of a collagen-HA coating ( $\mathrm{Li}$ et al., 2010) clearly demonstrating the potential of a composite material composed of only collagen and hydroxyapatite for use as a bioactive bone graft.

One of the barriers to the successful development of a collagen-HA scaffold is the difficulty in achieving a homogenous distribution of the HA throughout polymerbased matrices (Supová, 2009), an issue that can have a significant effect on a collagen-HA biomaterial's in vivo vascularisation and production of newly formed bone tissue (Lyons et al., 2010; Zhang et al., 2010a). As a result, many recent studies have utilised biocompatible or bioactive dispersants, such as chitosan (Zhang et al., 2010b) or biomimetic fabrication methods for the in situ mineralisation of collagen-HA scaffolds during the fabrication process (Kikuchi et al., 2004; Xu et al., 2010; Yoshida et al., 2010; Zhang et al., 2010a). However, control and regulation of this process and the resulting nature of the fabricated HA can be difficult with implications for the purity and crystallinity of the resulting mineral phase. Given that HA crystallinity and purity plays a significant role in promoting bone tissue formation in vivo (ter Brugge et al., 2002; Zhang et al., 2010a), the ability to produce pure collagen-HA scaffolds of high purity and crystallinity is desirable from a tissue engineering perspective.

Our laboratory's approach has involved the development a number of highly porous and biocompatible collagen-based scaffolds optimised in terms of composition (Tierney et al., 2009a; Tierney et al., 2009b), cross linking density (Haugh et al., 2009) and pore architecture (O'Brien et al., 2005; O'Brien et al., 2007a; Murphy et al., 2010a,b) for use in bone tissue engineering applications. Collagen is an ideal material when used as a scaffold as it fulfils many of the biological determinants required for successful implantation such as biocompatibility, cell adhesion and proliferation (Doillon et al., 1986; Berry et al., 2004; O’Brien et al., 2005; Byrne et al., 2008; Murphy et al., 2010a,b). Unfortunately, these scaffolds do not possess the load-bearing capability required when used in orthopaedic tissue engineering applications.

The aim of this study was to develop a biomimetic and highly porous ( $>95 \%$ ) composite scaffold by incorporating an osteoinductive ceramic phase into our optimised collagen-based scaffolds and to assess its regenerative potential as a bone graft substitute. Our approach seeks to optimise a compliant scaffold to promote mineralisation upon implantation (Hutmacher et al., 2000), rapidly facilitating a load bearing capacity within the newly mineralised bone tissue graft. By combining the two primary constituents of human bone tissue, namely type 1 collagen and hydroxyapatite using a patented mixing process (O'Brien et al., 2007b, WO200896334A2), a highly porous composite tissue engineering scaffold with a high degree of pore interconnectivity, improved mechanical strength, permeability and cellular bioactivity was developed. The combination of the extremely biocompatible and biodegradable collagen scaffold with an osteoinductive mineral component (Gosain et al., 2002; Yuan et al., 2002; Barrere et al., 2003; Le Nihouannen et al., 2005; Habibovic et al., 2006) provides an ideal mechanical and biological environment to facilitate cell recruitment and maintain pore structure in order to promote healing. The objective of this study was to investigate the effect of the addition of HA to our highly porous collagen scaffolds on (i) mechanical stiffness, (ii) scaffold porosity, (iii) pore interconnectivity (measured in terms of permeability), (iv) in vitro osteogenic potential and (v) in vivo healing potential of these biomimetic scaffolds.

\section{Materials and Methods}

\section{Scaffold fabrication}

Collagen slurries were produced by the homogenisation of fibrillar collagen (Collagen Matrix, Franklin Lakes, NJ, USA) within a $0.5 \mathrm{M}$ acetic acid solution. Slurries were homogenised in a reaction vessel, cooled to $4^{\circ} \mathrm{C}$ by a WK1250 cooling system (Lauda, Westbury, NY, USA), using an overhead blender (IKA Works Inc., Wilmington, NC, USA). In parallel, hydroxyapatite (HA) particles with a mean particle diameter of $5 \mu \mathrm{m}$ (Plasma Biotal Limited, North Derbyshire, UK) were suspended in a $0.5 \mathrm{M}$ acetic acid solution. The final collagen-hydroxyapatite (CHA) composite slurry was produced by the addition, in aliquots, of the HA/acetic acid suspension to the initial collagen slurry during the homogenisation process. Collagen concentration in all scaffolds was $0.1 \mathrm{~g}$ per $\mathrm{ml}$ acetic acid solution. HA concentration within the CHA scaffolds was varied as a weight percentage of the collagen concentration, resulting in four distinct scaffolds, namely control collagenonly ( $0 \mathrm{wt} \% \mathrm{HA}), 50 \mathrm{wt} \% \mathrm{HA}, 100 \mathrm{wt} \% \mathrm{HA}$ and $200 \mathrm{wt} \%$ HA scaffolds $(0 \mathrm{~g} \mathrm{HA} / \mathrm{ml}, 0.05 \mathrm{~g} \mathrm{HA} / \mathrm{ml}, 0.1 \mathrm{~g} \mathrm{HA} / \mathrm{ml}$ and $0.2 \mathrm{~g} \mathrm{HA} / \mathrm{ml}$ respectively). The resulting solution was degassed to remove any air bubbles and subsequently stored at $4^{\circ} \mathrm{C}$ prior to lyophilisation.

Collagen and CHA scaffolds were fabricated using a previously described lyophilisation technique by O'Brien et al. (2004; 2005). Briefly, $67.25 \mathrm{ml}$ of the CHA slurry was pipetted into a stainless steel pan $(125 \times 125 \mathrm{~mm}$, grade $304 \mathrm{SS}$ ). The tray was placed onto the freeze-dryer shelf (Advantage EL, Vir-Tis Co., Gardiner, NY, USA) and cooled to $-40^{\circ} \mathrm{C}$ at a constant cooling rate of $0.9^{\circ} \mathrm{C} /$ min. Once freezing was complete, the ice crystals were removed by sublimation for $17 \mathrm{~h}$ at $0^{\circ} \mathrm{C}$ and 200 mTorr. This process produces a highly porous sheet of scaffold of dimensions $125 \mathrm{~mm}$ (W) x $125 \mathrm{~mm}$ (L) x $4 \mathrm{~mm}$ (D). Dehydrothermal (DHT) cross linking treatment was carried out as previously described (Haugh et al., 2009) by placing the scaffolds in an aluminium foil packet inside a vacuum 
oven (Vacucell 22, MMM, Brno, Czech Republic) under a vacuum of 0.05 bar at a temperature of $120^{\circ} \mathrm{C}$ for 24 hours. This process improves the mechanical properties and also sterilises the scaffolds. Scaffold samples were further cross linked by immersion in an EDC/NHS solution (14 mM N(3-Dimethylaminopropyl) -N'-ethylcarbodiimide hydrochloride/5.5 mM N-hydroxysuccinimide; SigmaAldrich, St. Louis, MO, USA) for two hours (Haugh et al., 2009) to additionally improve the mechanical characteristics of the scaffolds.

The microstructure of the different scaffolds was examined after their production. No significant difference was found between the average pore size of the scaffold groups, with the average pore size seen to be $120 \mu \mathrm{m}$. Average pore size was not altered by the addition of HA particles. This allowed the exclusion of pore size as a variable. Hydroxyapatite particle distribution was assessed using Energy Dispersive X-Ray analysis and microCT and particles were found to be homogenously distributed in all three CHA scaffold groups. Particle size was assessed qualitatively using scanning electron microscopy (SEM) and was found to be unaffected by the fabrication process.

\section{Mechanical testing}

Unconfined compression testing was carried out using a mechanical testing machine (Z050, Zwick/Roell, Ulm, Germany) fitted with a 5-N load cell. Samples $(n=20)$ were prehydrated in phosphate buffered saline (PBS) for 1 hour prior to testing and all testing was carried out with samples submerged in a bath of PBS. Samples of $9.5 \mathrm{~mm}$ diameter were cut from the scaffolds using a punch and were subsequently placed between two impermeable, unlubricated platens. Compressive tests were conducted up to a maximum compressive strain of $10 \%$, at a strain rate of $10 \%$ per minute. The compressive modulus was defined as the slope of a linear fit to the stress-strain curve over 2-5\% strain (Haugh et al., 2009).

\section{Scaffold porosity}

The dry weight of $9.5 \mathrm{~mm}$ diameter scaffold samples was determined using a mass balance, with height and diameter measured using digital Vernier callipers (Krunstoffwerke, Radionics, Dublin, Ireland) to determine scaffold sample volume. The relative density of the scaffolds was calculated from the dry weight and volume of each scaffold disc using the density of bulk collagen $\left(1.3 \mathrm{mg} / \mathrm{mm}^{3}\right)$ and hydroxyapatite $\left(3.153 \mathrm{mg} / \mathrm{mm}^{3}\right)$. The percentage porosity was calculated using eqn (1) below;

$$
\text { Porosity }(\%)=\left(1-\rho_{\text {scaffold }} / \rho_{\text {solid }}\right) \times 100
$$

Results of eight measurements $(n=8)$ were averaged to determine mean scaffold porosity for each scaffold variant (Tierney et al., 2009a).

\section{Scaffold permeability}

Scaffold pore interconnectivity was assessed by quantifying fluid mobility (permeability) of the scaffolds. Scaffold samples were inserted into a custom permeability rig under a column of water. Validation experiments were carried out to validate fluid flow through the compliant scaffolds. The flow rate of water through the constructs $(n=5)$ was measured over a flow period of 300 seconds and used to calculate the steady state permeability from eqn (2);

$$
k=Q h / A P
$$

where $k$ is the hydraulic permeability in $\mathrm{m}^{4} / \mathrm{Ns}, Q$ is the volume flow rate in $\mathrm{m}^{3} / \mathrm{s}, h$ is the height of the scaffold, $A$ is the cross sectional area of the flow path and $P$ is the pressure of the column of water, given by eqn (3):

$$
P=\rho g h
$$

where $\rho$ is the density of water, $g$ is the acceleration due to gravity and $h$ is the height of the water column used.

\section{Cell culture}

Scaffold samples were seeded with 2 million MC3T3-E1 pre-osteoblast cells (ATCC-LGC, Teddington, Middlesex, UK). Cell-seeded scaffolds were cultured in nonosteogenic media (alpha-minimum essential medium $(\alpha-$ MEM), BioSera, East Sussex, UK) supplemented with 2\% penicillin/streptomycin, 1\% L-glutamine, $10 \%$ foetal bovine serum and $0.1 \%$ amphotericin (Sigma-Aldrich Ireland, Dublin, Ireland) for 3 days to allow proliferation before the medium was supplemented with osteogenic factors $(10 \mathrm{mM} \beta$-glycerophosphate and $50 \mu \mathrm{g} / \mathrm{mL}$ ascorbic acid (Sigma-Aldrich). Cell-seeded scaffolds were cultured for $7,14,21$ and 28 days at a temperature of $37^{\circ} \mathrm{C}$ and a carbon dioxide concentration of $5 \% \mathrm{CO}_{2}$. The osteogenic medium was changed every 2 to 3 days during the culture period.

\section{DNA quantification}

Four scaffolds $(n=4)$ per group (collagen-only, $50 \mathrm{wt} \%$ HA, $100 \mathrm{wt} \% \mathrm{HA}, 200 \mathrm{wt} \% \mathrm{HA}$ ) at each of the four time points (64 samples in total) were homogenised in $1 \mathrm{~mL}$ of Qiazol (Qiagen, Valencia, CA, USA) using a high speed, hand-held homogeniser (Finemech, Portola Valley, CA, USA) equipped with a T6 homogenising shaft attachment (Finemech). After the addition of chloroform and centrifugation to separate RNA and DNA, the RNA layer was pipetted off carefully and stored. Cell number on the constructs was quantified using a Hoechst 33258 assay (Sigma-Aldrich). The fluorescence of the samples was measured at $460 \mathrm{~nm}$ after excitation at $355 \mathrm{~nm}$ in a Wallac Victor2TM 1420 multilabel counter (Perkin Elmer Life Sciences, Waltham, MA, USA) and compared to a standard curve to determine cell number.

\section{Histological analysis}

At each time point, scaffold samples were placed into a solution of $10 \%$ formalin for $30 \mathrm{~min}$ and then processed with an automatic tissue processor (ASP300, Leica, Wetzlar, Germany). All constructs were embedded in paraffin wax and sectioned at a thickness of $10 \mu \mathrm{m}$ using a rotary microtome (RM2255, Leica microtome, Leica). Sections were placed in an oven at $70^{\circ} \mathrm{C}$ overnight and 

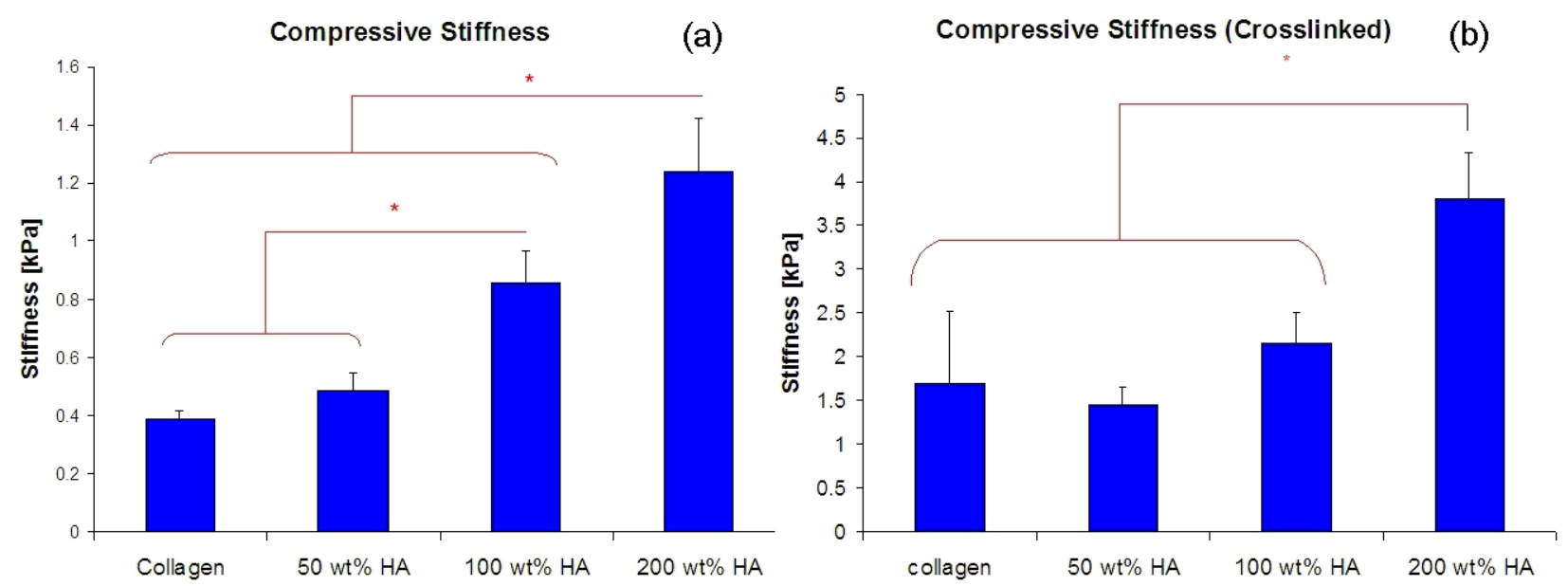

Fig. 1. (a) Effect of hydroxyapatite addition on the compressive stiffness of collagen-based scaffolds $\left({ }^{*} p<0.05\right)$; (b) Effect of hydroxyapatite addition on the compressive stiffness of DHT and chemically cross linked collagen-based scaffolds $\left({ }^{*} p<0.05\right)$. The addition of hydroxyapatite results in a linear increase in wet unconfined compressive stiffness in both non-cross-linked $\left(\mathrm{R}^{2}=0.99\right)$ and cross linked $\left(\mathrm{R}^{2}=0.95\right)$ CHA scaffolds. Cross-linked $200 \mathrm{wt} \%$ HA scaffold is ten times stiffer than non-cross linked collagen-only scaffolds $(0.4 \mathrm{kPa}$ vs. $4 \mathrm{kPa})$.

residual wax was removed from the sections in a xylene bath. Sections were stained in $2 \%$ alizarin red for $5 \mathrm{~min}$ after wax removal and hydration. Quantification of mineralisation was carried out using $10 \%$ cetylpyridinium chloride to absorb the alizarin red stain from sections that had been exposed to this stain (Venugopal et al., 2008). Four scaffold sections were attached per slide: two per slide were quantified, leaving two other sections per slide for examination under the microscope. $400 \mu 1$ of cetylpyridinium chloride solution was pipetted onto the slides and the stain was desorbed for 15 minutes. $100 \mu \mathrm{l}$ was pipetted in triplicate into the wells of a 96 well plate. Absorbance readings at $540 \mathrm{~nm}$ were obtained on a Titerek Multiskan MCC/340 spectrometer (Titertek, Pforzheim, Germany) after subtraction of cetylpyridinium solution baseline readings. Digital images of all stained sections were captured at $200 \mathrm{X}$ magnification using an imaging system (AnalySIS, Olympus, Tokyo, Japan or NIS Elements Basic Research Version 3.0, Nikon, Tokyo, Japan) in conjunction with a microscope (Olympus IX51 or Nikon Eclipse 90i).

\section{Pre-clinical trial}

A small preliminary pre-clinical trial was carried out to investigate the regenerative potential of the collagen hydroxyapatite (CHA) scaffolds. Pre-clinical investigation was carried out under approval by the RCSI Research Ethics Committee and following acquisition of an animal license from the Irish Government Department of Health. $5 \mathrm{~mm}$ diameter transosseous critical sized defects were created in calvariae of 3 adult Wistar rats. One animal was left with an empty defect as a control. The remaining two calvarial defects were filled with the optimised $200 \mathrm{wt} \%$ HA scaffolds. Animals were anaesthetised prior to surgical intervention. Calvarial bone was exposed and a criticallysized defect was introduced into the bone ( $5 \mathrm{~mm}$ diameter) using a trephine bur. Scaffolds were located within these cylindrical defect sites. The periosteum was subsequently sutured over the scaffold-filled defect, followed by suturing of the skin. Animals were closely monitored postoperatively with regular administration of suitable antibiotics and analgesias. After 28 days implantation within the rat calvariae, the animals were sacrificed and the calvarial bones were removed. These were analysed using microCT to investigate the capacity of the $200 \mathrm{wt} \%$ HA scaffold to promote healing. Scans were performed on a Scanco Medical 40 Micro CT system (Bassersdorf, Switzerland) with $70 \mathrm{kVP}$ X-ray source and $112 \mu \mathrm{A}$ using a high-resolution of $8 \mu \mathrm{m}$. Due to the high porosity of the CHA scaffolds, a threshold level greater than 35 renders the scaffold invisible (Al-Munajjed et al., 2009) and a threshold of 140 (grayscale value between 0 and 1000) was required to image mineralised tissue (Kennedy et al., 2009). Consequently a threshold value of 140 was used to assess new host tissue mineralisation within the defects without any influence of the original porous CHA scaffold.

\section{Statistical analysis}

All error bars represent standard deviations. Statistical analysis was carried out using Minitab 15 (Minitab Inc., State College, PA, USA) by applying a general linear model ANOVA with the Tukey test as the post-hoc test. Nonnormal data was normalised using logarithmic or square root transforms so that the conditions of the statistical test were met. Statistical significance was taken at $p<0.05$.

\section{Results}

\section{Compressive stiffness}

The addition of hydroxyapatite particles added to the collagen scaffolds in $50 \mathrm{wt} \%, 100 \mathrm{wt} \%$ and $200 \mathrm{wt} \%$ quantities resulted in an approximately linear increase $\left(\mathrm{R}^{2}=0.99\right)$ in unconfined compressive stiffness of the hydrated scaffolds. Average stiffness values for the noncross linked $50 \mathrm{wt} \%, 100 \mathrm{wt} \%$ and $200 \mathrm{wt} \%$ HA scaffolds were approximately $0.5 \mathrm{kPa}, 0.9 \mathrm{kPa}$ and $1.3 \mathrm{kPa}$ respectively, with the $200 \mathrm{wt} \% \mathrm{HA}$ scaffolds being 


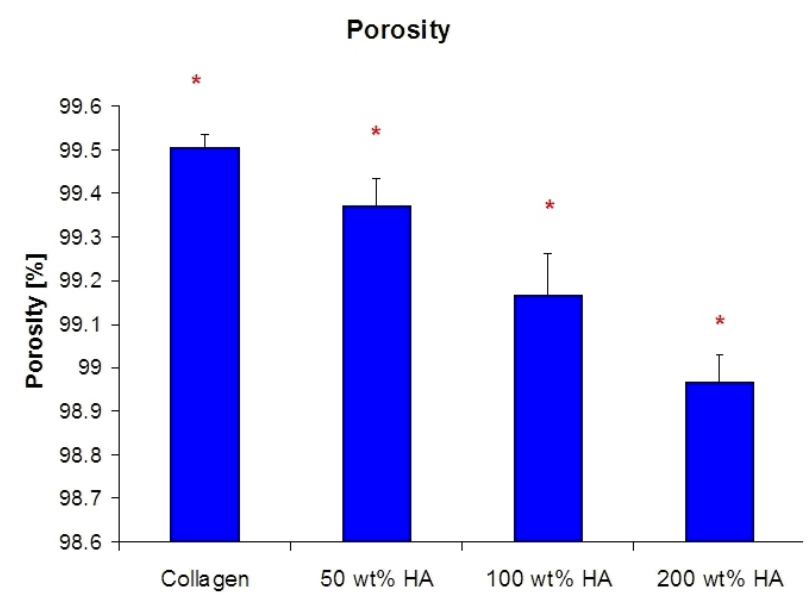

Fig. 2. Effect of hydroxyapatite addition on the porosity of collagen-based scaffolds $(* p<0.05)$. The addition of hydroxyapatite results in statistically significant but negligible linear decrease $\left(\mathrm{R}^{2}=0.99\right)$ in overall scaffold porosity for all groups. The $200 \mathrm{wt} \%$ HA scaffold porosity is still as high as $99 \%$.

significantly stiffer than all other scaffolds $(p<0.05)$ (Fig. 1a). A similar trend $\left(R^{2}=0.95\right)$ was seen in all scaffold variants after the scaffold groups were dehydrothermally and chemically cross linked, with the absolute stiffness values being substantially increased as the quantity of $\mathrm{HA}$ added was increased (1.5 kPa, $2.2 \mathrm{kPa}$ and $3.5 \mathrm{kPa}$ respectively) (Fig. 1b), with the $200 \mathrm{wt} \%$ HA scaffolds showing a nearly tenfold increase in mechanical stiffness $(p<0.05)$ relative to non-cross linked collagen controls.

\section{Construct porosity}

Average scaffold porosity significantly decreased $(p<0.05)$ as the quantity of HA was increased as function of collagen weight (Fig. 2). Collagen controls were found to exhibit an average porosity of approximately $99.5 \%$, with porosity levels decreasing in an approximately linear fashion $\left(\mathrm{R}^{2}=0.99\right)$ as the quantity of HA was increased to $50 \mathrm{wt} \%$ HA, $100 \mathrm{wt} \%$ HA and $200 \mathrm{wt} \%$ HA $(99.4 \%, 99.2 \%$ and $99 \%$ respectively). This decrease in scaffold porosity level was expected due to the addition of HA but was negligible in real terms, even in the $200 \mathrm{wt} \%$ HA scaffolds. The largest decrease in porosity was seen in the $200 \mathrm{wt} \%$ HA scaffolds

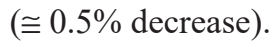

\section{Construct permeability}

Scaffold permeability was seen to increase in an approximately linear fashion $\left(\mathrm{R}^{2}=0.97\right)$ as the quantity of HA added to the scaffold increased up to $200 \mathrm{wt} \%$ HA. 50 $w t \%$ HA scaffolds exhibited a significantly higher permeability relative to collagen control scaffolds $(p<0.05)$ while $100 \mathrm{wt} \% \mathrm{HA}$ and $200 \mathrm{wt} \%$ HA scaffolds were significantly more permeable than $50 \mathrm{wt} \%$ HA scaffolds and controls (Fig. 3).

\section{DNA quantification}

Cells were viable on all scaffolds at every time point up to 28 days based on cell number quantification. Cell number was seen to significantly increase $(p<0.05)$ in the $50 \mathrm{wt} \%$

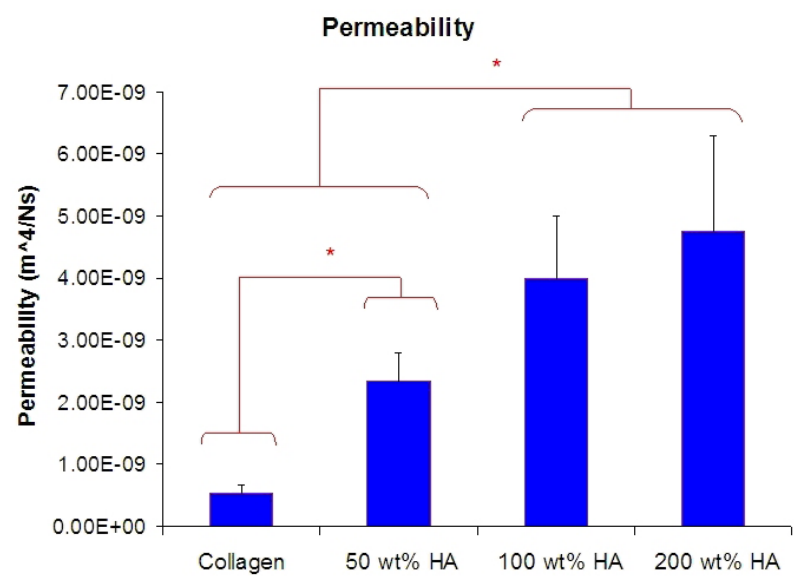

Fig. 3. Effect of hydroxyapatite addition on scaffold permeability $(* p<0.05)$. The addition of hydroxyapatite results in a linear increase $\left(\mathrm{R}^{2}=0.97\right)$ in scaffold permeability for all CHA scaffold groups. $200 \mathrm{wt} \% \mathrm{HA}$ scaffold is approximately ten times more permeable than collagen-only scaffolds $\left(0.4 \times 10^{-9} \mathrm{~m}^{4} / \mathrm{Ns}\right.$ vs. $4.5 \times 10^{-9}$ $\left.\mathrm{m}^{4} / \mathrm{Ns}\right)$.

\section{Proliferation (cell number at 7 days minus cel number at 28 days)}

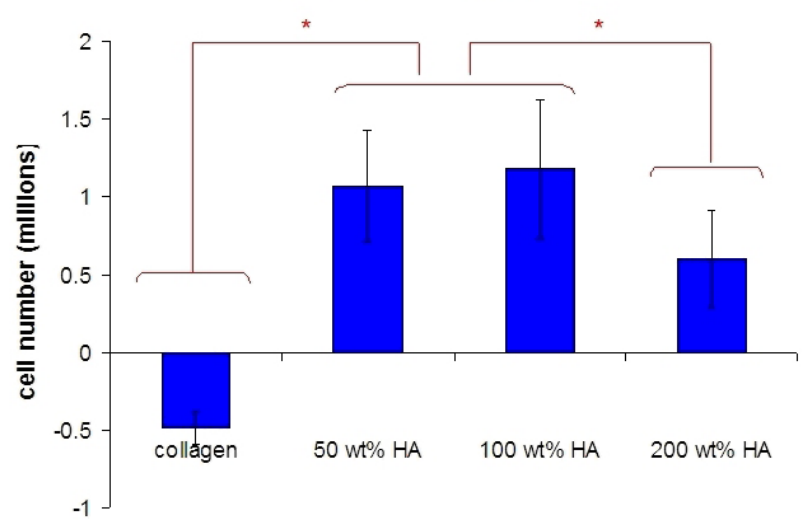

Fig. 4. Effect of hydroxyapatite addition on scaffold bioactivity $(* p<0.05)$. The addition of hydroxyapatite resulted in a significantly increase $(p<0.05)$ in cell number in the $50 \mathrm{wt} \%$ and $100 \mathrm{wt} \%$ HA scaffolds while $200 \mathrm{wt} \%$ HA scaffolds exhibited a non-significant increase in number relative to collagen-only controls over the 28 day culture period.

and $100 \mathrm{wt} \%$ HA scaffolds while $200 \mathrm{wt} \%$ HA scaffolds exhibited a non significant increase in cell number relative to collagen-only controls over the 28 day culture period (Fig. 4).

\section{In vitro mineralisation}

$200 \mathrm{wt} \%$ HA scaffolds seeded with cells and cultured in vitro were the only group at days 14 and 21 that exhibited evidence of mineralisation. After the 28 day culture period, collagen-only scaffolds showed deeper mineralisation staining than the blank scaffolds while $50 \mathrm{wt} \%, 100 \mathrm{wt} \%$ and particularly $200 \mathrm{wt} \%$ HA constructs stained positive for calcium deposition (Fig. 5). Alizarin red stain quantification showed significantly increased staining 

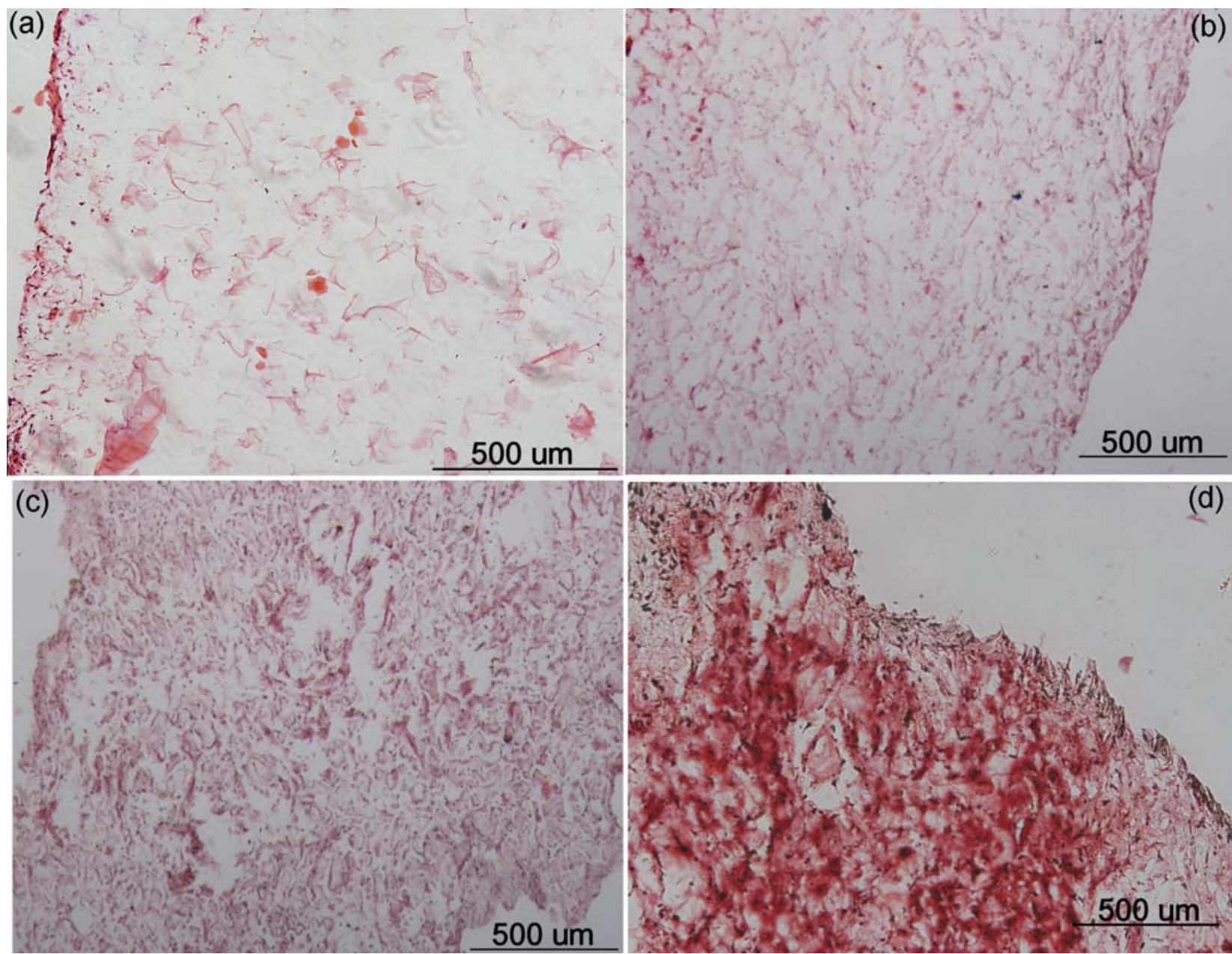

Fig. 5. Alizarin red staining of all four scaffold groups after 28 days in culture (A: Collagen-only, B: $50 \mathrm{wt} \% \mathrm{HA}, \mathbf{C}$ : $100 \mathrm{wt} \%$ HA, D: 200 wt $\%$ HA). Collagen-only scaffolds show no negligible Alizarin red staining. $50 \mathrm{wt} \%$ and 100 wt $\%$ HA groups show increased staining while $200 \mathrm{wt} \%$ HA group shows the highest levels of Alizarin red staining.

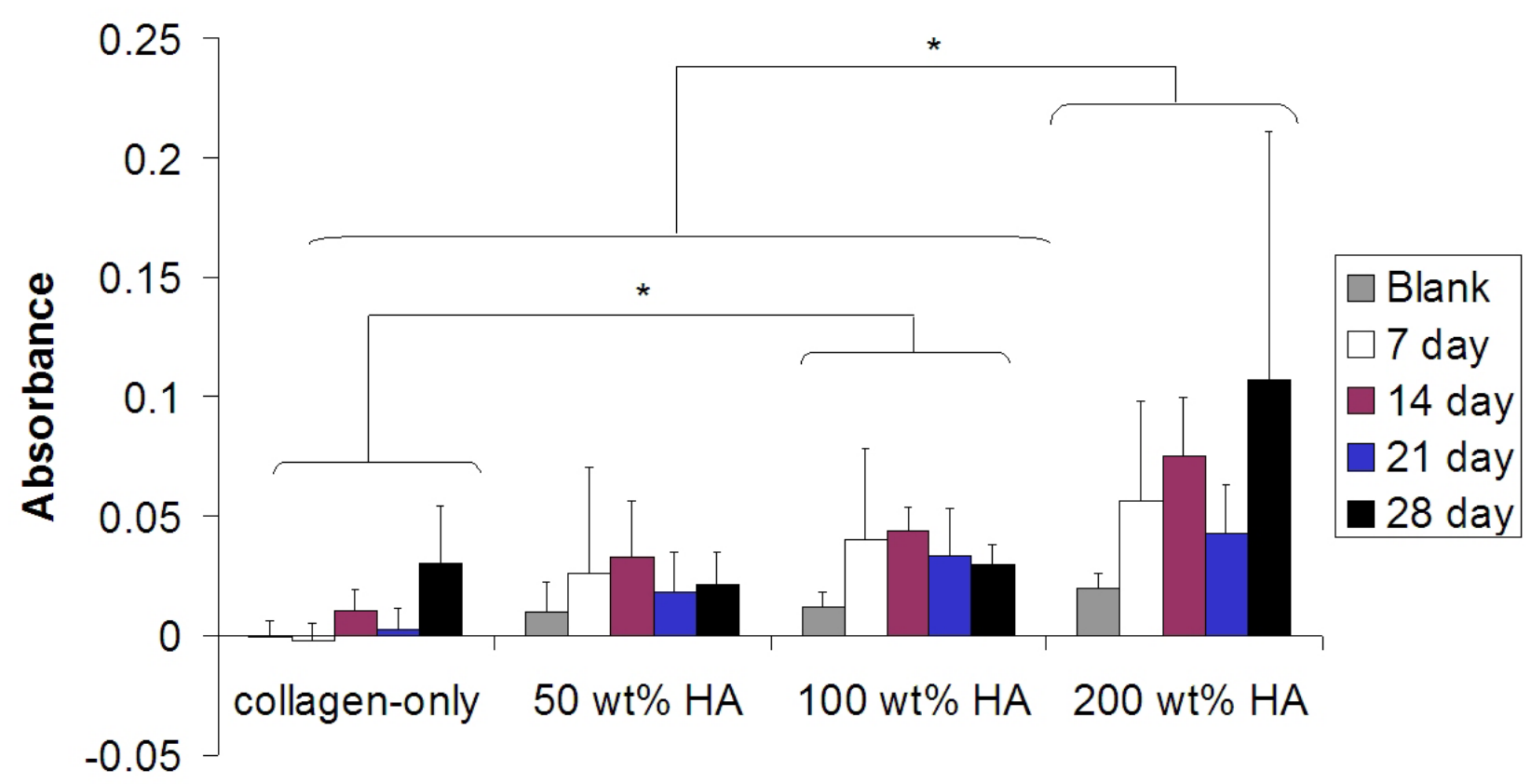

Fig. 6. Quantified alizarin red readings for the four groups over the 28 day culture period ( ${ }^{*} p<0.05$ ). These results confirm histological results. Collagen-only scaffolds show no significant Alizarin red staining, $50 \mathrm{wt} \%$ and $100 \mathrm{wt} \%$ HA groups show staining which is significantly higher than collagen-only staining in the $100 \mathrm{wt} \%$ HA group while the $200 \mathrm{wt} \%$ HA group shows the highest levels of staining which is significantly increased relative to all other groups. 

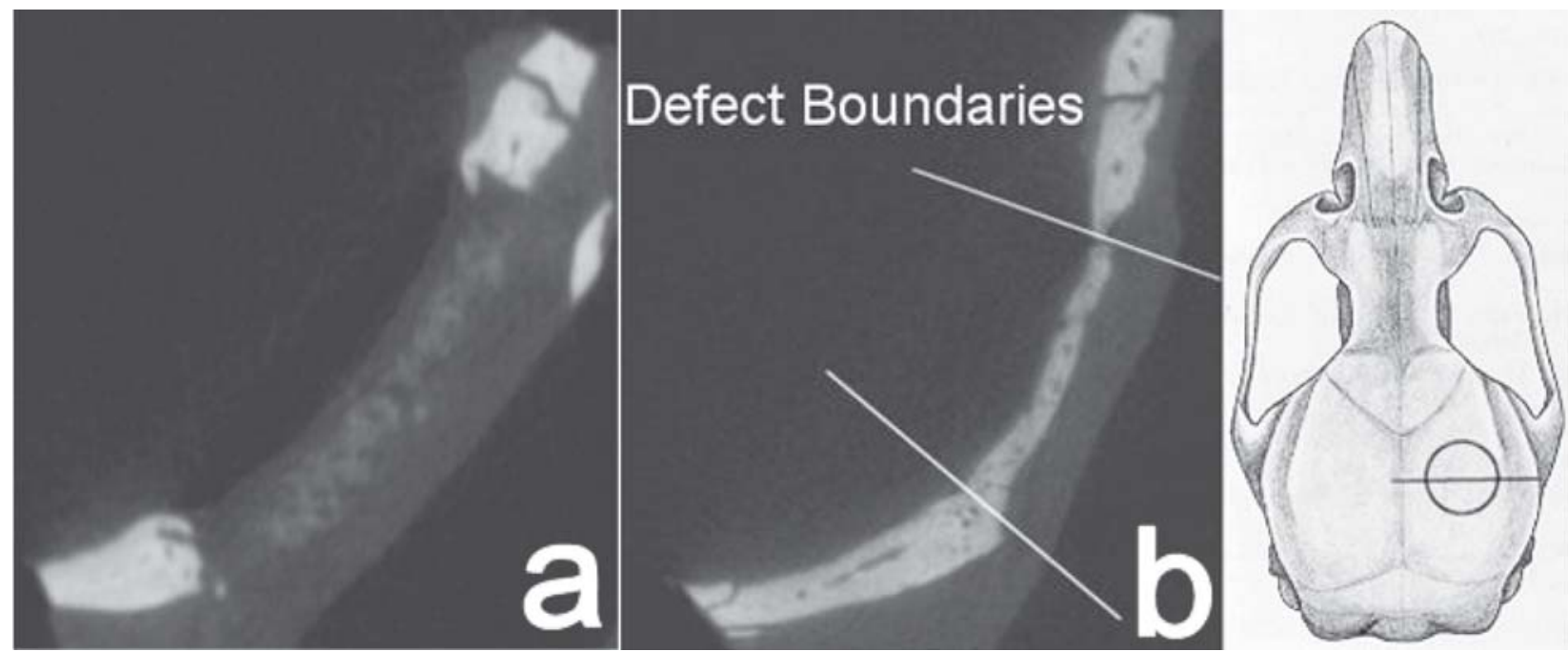

Fig. 7. MicroCT slice of representative level of mineralisation within the defect centre showing defect boundary edges in (a) empty defect group, (b) $200 \mathrm{wt} \%$ HA scaffold group after 28 days implantation with schematic of rat skull highlighting slice anatomical location. Almost complete defect bridging was observed in the $200 \mathrm{wt} \% \mathrm{HA}$ group, with mineralisation level comparable to surrounding native calvarial bone tissue.

$(p<0.05)$ of the $200 \mathrm{wt} \%$ HA scaffolds compared to the $100 \mathrm{wt} \% \mathrm{HA}, 50 \mathrm{wt} \%$ HA and collagen-only scaffolds (Fig. 6). $100 \mathrm{wt} \%$ HA scaffolds showed significantly elevated staining compared to the collagen-only scaffold $(p<0.05) .50 \mathrm{wt} \%$ HA scaffold mineralisation was nonsignificantly increased after 28 days in culture compared to the collagen-only scaffolds. By 28 days, there was significantly increased staining in the $200 \mathrm{wt} \% \mathrm{HA}$ scaffolds compared to all other cultured scaffold groups and the blank scaffolds $(p<0.05)$.

\section{Pre-clinical trial}

Throughout the study period, animals showed no signs of body weight loss or other deterioration in general health following surgery. The animals appeared healthy and alert and showed no signs of pain or discomfort. In the animal with an unfilled defect, the defect was filled in with loose fibrous tissue. Some evidence of localised mineralisation loci were seen within the empty defect after 28 days, in the form of small particles of dense material but these were sparsely distributed and not sufficiently dense to indicate significant healing within the empty defect sample. The $200 \mathrm{wt} \%$ HA samples showed significant levels of mineralisation at the periphery and were seen to progress towards the centre of the critical sized defects. This mineralised tissue was continuous in nature and was almost full thickness across the width of the defect (Fig. 7).

\section{Discussion}

The aim of this study was to develop a biomimetic scaffold by incorporating osteoinductive hydroxyapatite (HA) particles into a highly porous and extremely biocompatible collagen-based scaffold developed within our laboratory over the last number of years and to investigate the effect on osteogenic capacity of these scaffolds as potential bone graft substitutes. Current clinical standards of autografts and allografts are associated with donor site morbidity, limited volume of donor tissue, disease transmission, infection and chronic pain. Attention has turned to alternative treatments including bone tissue engineering but despite numerous teams worldwide working in the area, progress to date in engineering significant quantities of functional bone tissue in vitro for implantation has been disappointing (Meikle, 2007; Partap et al., 2010). Alternatively, regeneration of bone tissue in situ using tissue engineering scaffolds as potential bone graft substitutes, comprised of collagen and hydroxyapatite, has been attempted by numerous studies in the past (Swetha et al., 2010; Dawson et al., 2008) but this approach has shown limited clinical success (Ilan and Ladd, 2003; Barrere et al., 2008; Carter et al., 2009). One reason for this lack of success is the issue of core degradation, arising from lack of nutrient delivery and waste removal from the centre of tissue engineered constructs. This is caused by insufficient blood supply to the implanted tissue. As a result, tissue engineered constructs that appear to demonstrate great potential in vitro often fail once implanted in vivo due to acellular necrosis. This is of major concern in the field of tissue engineering, and is a major obstacle in the formation of a viable tissue in vitro. With this in mind, we hypothesised that the combination of a strong reinforcing and osteoinductive ceramic phase (HA) with a tough but biodegradable polymer phase (type I collagen) would produce a highly porous composite structure which possesses all the prerequisite biological, morphological and mechanical characteristics necessary to facilitate the body's own natural bone regenerative process in vivo. The results showed that the high porosity achieved in this scaffold, combined with the increased mechanical properties and improved permeability, seen as a result of the addition of the osteoinductive HA phase, make this scaffold an ideal template for the promotion of cell ingrowth and in vivo vascularisation.

Mechanical properties of tissue engineering scaffolds are vital to ensure long-term structural and functional viability in vivo. In addition, substrate mechanical 
properties of these scaffolds have been shown to be a determining factor in directing cellular activity (Engler $e t$ al., 2004; Engler et al., 2006). The addition of hydroxyapatite and the application of DHT and chemical cross-linking treatments resulted in a significant increase in scaffold mechanical stiffness. When $200 \mathrm{wt} \%$ HA was added in conjunction with DHT and chemical cross linking treatments, an approximate ten-fold increase in substrate stiffness was achieved, specifically up to $4 \mathrm{kPa}$. Recent unpublished work from our laboratory has demonstrated that collagen-based scaffolds with a stiffness in this range exhibit increased cell attachment, proliferation and migration compared to less stiff scaffolds. From a bone tissue regeneration perspective, these scaffolds are within a bulk stiffness range close to that shown to favour osteogenic differentiation of mesenchymal stem cells (MSCs) (Engler et al., 2006). Interestingly, recent studies have investigated the bulk and localised mechanical properties of collagen-based scaffolds manufactured using an identical fabrication process to the one employed in this study (Harley et al., 2007). The nature of high porosity structures means that their bulk mechanical properties are dramatically different to the mechanical properties of the individual struts within the open foam network. As a result, the substrate stiffness that a cell 'feels' while attached to one or multiple struts within the porous scaffold can be significantly higher than that predicted by bulk assessment of the material. Based on their study, it was estimated that the substrate stiffness experienced by a cell attached within a CHA scaffold pore would be of the order of approximately 50 to $100 \mathrm{MPa}$. This level of localised strut stiffness would appear to be sufficiently high to promote osteogenic differentiation (Khatiwala et al., 2007; Rowlands et al., 2008) but comparisons are difficult as these substrate stiffness studies were carried within twodimensional environments as distinct from the threedimensional environment of the CHA scaffolds. Due to the relatively small pore size in the scaffolds produced using the lyophilisation technique used in this study, the stiffness the cell's actually sense will be governed by a combination of both bulk and tissue modulus because, it is known from research carried out in our laboratory, that up to $75 \%$ of cells will bridge pores (Jungreuthmayer et al., 2009) and thus they are not seeing a flat planar surface (i.e. a $2 \mathrm{D}$ environment). Therefore, the effect of local substrate stiffness in a three-dimensional environment such as that of the CHA scaffold is still an area that requires significant future investigation. However, what is clear is that these scaffolds clearly show potential for bone tissue regeneration when implanted into either an osteoprogenitor-rich osseous defect (such as oral or maxillofacial reconstruction) or alternatively as a bone void filler, used in load-bearing bone tissue defects in combination with mechanical fixation.

All scaffolds investigated as part of this study exhibited an extremely high degree of porosity (99.5\%). While the addition of hydroxyapatite in increasing quantities up to $200 \mathrm{wt} \%$ relative to scaffold collagen weight resulted in an expected decrease in scaffold porosity level, this decrease was negligible in real terms, even in the $200 \mathrm{wt} \%$
HA scaffolds where a porosity as a high as 99\% was maintained. This exceeded our goal of achieving a porosity as high as $95 \%$ while improving the mechanical properties compared to the collagen-only scaffold. Porosity is a critical characteristic of tissue engineering scaffolds as high levels of porosity play a critical role in in vitro and in vivo bone formation (Karageorgiou and Kaplan, 2005). Higher scaffold porosity has been shown to increase cell proliferation levels, due to improved transport of oxygen and nutrients (Takahashi and Tabata, 2004) as a result of increased vascularity which results in an increase in bone ingrowth and new bone formation in vivo (Roy et al., 2003).

Flow conductivity or permeability is a measure of the resistance within a porous construct to fluid flow under pressure. High permeability scaffolds are attractive from a tissue engineering point of view as they facilitate increased levels of fluid flow in vivo and consequent cellular diffusion. Fluid flow has also been shown in a number of studies to have a stimulatory effect on earlystage bone formation markers in three-dimensional tissue engineering scaffolds (Jaasma and O'Brien, 2008) and stimulating mineral deposition in vitro (Bancroft et al., 2002; Sikavitsas et al., 2005). The extremely high level of porosity retained in scaffolds fabricated using twice as much hydroxyapatite per weight than collagen ensures a high degree of pore interconnectivity and presents an extremely large internal surface area for cellular attachment (O'Brien et al., 2005). Permeability values increased significantly in all CHA scaffolds relative to collagen-only scaffolds. It can be hypothesised that this increase in permeability is directly related to the incremental increase in scaffold stiffness as the proportion of hydroxyapatite was increased. Scaffolds possessing increased mechanical stiffness would be better able to withstand the hydrostatic pressure and this resistance to deformation would have a significant benefit in terms of pore shape and size retention, reducing resistance to fluid flow under constant pressure. It could be postulated that this effect would have a positive effect in vivo by ensuring high levels of fluid diffusion and cellular material perfusion throughout the scaffolds during low level in vivo loading, ensuring homogenous cellular attachment, proliferation and mineral deposition. Consequently, scaffolds with as much HA as $200 \mathrm{wt} \%$ can potentially provide an ideal environment capable of supporting long-term cellular attachment and proliferation while significantly reducing the threat of avascular necrosis occurring within the scaffold core during long-term in vitro cell culture and in vivo implantation (Kelly and Prendergast, 2004). This problem becomes increasingly manifested as cells on the periphery of the construct grow and secrete extracellular matrix. As a result, diffusion of nutrients to the centre of the construct becomes increasingly more difficult due to impeded movement of fluid into the core. The resulting encapsulation effect eventually leads to acellular necrosis occurring in the scaffold centre which acts as a major obstacle in the formation of a viable tissue in vitro (Plunkett et al., 2010). Thus, the high porosity achieved in this scaffold, combined with increased mechanical properties and improved 
permeability make it an ideal template to promote cell ingrowth and subsequent vascularisation and prevent the problem of core degradation occurring following implantation.

DNA quantification showed increased cell number on all CHA scaffold groups while in contrast, there was a modest decrease in the number of cells on collagen-only constructs over time. While some of these changes were not statistically significant, it is interesting to note that this increased trend was present on all CHA scaffolds. Critically, all CHA scaffold groups are at least as biocompatible as the collagen-only constructs. This is an important finding given collagen's well accepted position as a biocompatibility "gold standard" in tissue engineering and strongly supports the potential use of CHA scaffolds as potential bone graft substitutes.

A significant increase in cell-mediated mineral deposition was observed in scaffolds that exhibited the highest substrate stiffness, highest degree of permeability and contained the largest amount of the osteoinductive HA particles. The significant increase in alizarin red staining on $200 \mathrm{wt} \%$ HA scaffolds after 28 days in vitro culture is encouraging from an in vitro osteogenesis perspective. This calcium deposition was seen throughout the $200 \mathrm{wt} \%$ HA scaffolds at earlier time points but increased dramatically at 28 days. This result was promising as it illustrates the potential of the $200 \mathrm{wt} \%$ HA scaffolds to support the development of bone tissue from an osteoblast proliferation stage through to extra cellular matrix (ECM) deposition and on to cell-mediated early-stage mineralisation. Interestingly, this effect was not observed in the $50 \mathrm{wt} \%$ HA or the $100 \mathrm{wt} \%$ HA scaffolds after 28 days in culture. Clearly the addition of small amounts of HA to the scaffolds results in a significantly increased level of calcium deposition and has a mild osteogenic effect. However, there appeared to be a threshold level of $200 \mathrm{wt} \%$ HA required to cause a dramatic increase in the osteogenic potential of the scaffolds, seen in the $200 \mathrm{wt} \%$ HA 28 day scaffolds. The results of this study suggest that this may be due to two distinct effects as a result of the inclusion of hydroxyapatite particle within the composite, namely (i) the osteoinductive effect of the HA particles when their inclusion does not significantly increase scaffold stiffness (seen in the $100 \mathrm{wt} \%$ HA scaffolds, Fig. 1b) and (ii) the combination of the osteoinductive HA particles in combination with an increase in scaffold stiffness (seen in the $200 \mathrm{wt} \%$ HA scaffolds) that results in a dramatic increase in mineral deposition within the scaffolds after 28 days. The osteogenic influence of substrate stiffness alone has been seen previously (Engler et al., 2006) but clearly the ability to increase the substrate stiffness within these constructs using a biocompatible and osteoinductive HA phase has significant advantages in bone tissue engineering applications.

The regenerative potential of the $200 \mathrm{wt} \%$ HA scaffold was clearly observed in the pilot pre-clinical trial carried out as part of this study. After only 28 days implantation within a critical sized calvarial defect, evidence of new bone formation was observed with almost complete bridging of the defect. Most interestingly, mineralisation was seen to progress into the core of the circular osseous defect and was almost full thickness across the width of the defect. Mineralisation levels were comparable to the existing calvarial bone tissue, with an approximate mineralisation level of $75 \%$ assessed radiographically compared to normal bone tissue surrounding the defect. Although a larger study would be required to conclusively investigate the extent of bone regeneration possible, the data provide strong evidence for the regenerative potential of these scaffolds. Most importantly, it is clear that these scaffolds have the potential to support long-term healing of osseous defects and can support cellular infiltration and diffusion in vivo into their core. It remains to be seen whether these scaffolds could regenerate full thickness healing in load bearing defects greater than the current limits of scaffold diffusion but the mineralisation of the scaffold core to nearly full defect thickness seen in this preliminary study is promising. Additionally, the speed at which mineralisation occurred (approximate mineralisation level of $75 \%$ compared to the surrounding calvarial bone tissue) after only 28 days implantation strongly suggests that further investigation of these scaffolds in larger load bearing pre-clinical investigations is warranted.

\section{Conclusions}

In conclusion, a highly porous biomimetic tissue engineering scaffold has been developed that exhibits increased stiffness, interconnectivity and in vitro bioactivity due to the addition of an osteoinductive hydroxyapatite phase. This scaffold is comprised only of bone's natural constituent materials, ensuring non-toxic degradation by-products, excellent biocompatibility and the potential to degrade in parallel with the process of new bone formation in vivo. Coupled with the short-term in vitro and in vivo experimental results, this CHA scaffold demonstrates real potential as a bone graft substitute material, capable of facilitating and promoting osteogenesis in vivo.

\section{Acknowledgements}

The authors acknowledge Science Foundation Ireland, President of Ireland Young Researcher Award (04/Y11/ B531), Enterprise Ireland Proof of Concept Award (PC/ 2005/226) and Enterprise Ireland Commercialisation Fund Technology Development Award (TD/2007/112) for funding.

\section{References}

Al-Munajjed AA, Plunkett NA, Gleeson JP, Weber T, Jungreuthmayer C, Levingstone T, Hammer J, O’Brien FJ (2009) Development of a biomimetic collagenhydroxyapatite scaffold for bone tissue engineering using a SBF immersion technique. J Biomed Mater Res B Appl Biomater. 90: 584-591. 
Arrington ED, Smith WJ, Chambers HG, Bucknell AL, Davino NA (1996) Complications of iliac crest bone graft harvesting. Clin Orthop 329: 300-309.

Athanasiou KA, Agrawal CM, Barber FA, Burkhart SS (1998) Orthopaedic applications for PLA-PGA biodegradable polymers: Current concepts. Arthroscopy 14: 726-737.

Bancroft GN, Sikavitsas VI, van den Dolder J, Sheffield TL, Ambrose CG, Jansen JA, Mikos AG (2002) Fluid flow increases mineralized matrix deposition in $3 \mathrm{D}$ perfusion culture of marrow stromal osteoblasts in a dose-dependent manner. Proc Natl Acad Sci USA 99: 12600-12605.

Barrere F, van der Valk CM, Dalmeijer RA, Meijer G, van Blitterswijk CA, de Groot K Larolle P (2003) Osteogenecity of octacalcium phosphate coatings applied on porous metal implants. J Biomed Mater Res A 66: 779788.

Barrere F, Mahmood TA, de Groot K, van Blitterswijk CA (2008) Advanced biomaterials for skeletal tissue regeneration: Instructive and smart functions. Mat Sci Eng 59: 38-71.

Berry CC, Campbell G, Spadiccino A, Robertson M, Curtis AS (2004) The influence of microscale topography on fibroblast attachment and motility. Biomaterials 25: 5781-5788.

Bohner M (2000) Calcium orthophosphates in medicine: from ceramics to calcium phosphate cements. Injury 31: 37-47.

Bohner M, Van Landuyt P, Trophardy G, Merkle H, Lemaitre J (2000) Effect of several additives and their admixtures on the physicochemical properties of a calcium phosphate cement. J Mater Sci Mater Med 11:111-116.

Bridwell KH, O’Brien MF, Lenke LG, Baldus C, Blanke K (1994) Posterior spinal fusion supplemented with only allograft bone in paralytic scoliosis. Does it work? Spine 9: 2658-2666.

Byrne EM, Farrell E, McMahon LA, Haugh MG, O’Brien FJ, Campbell VA, Prendergast PJ, O'Connell BC (2008) Gene expression by marrow stromal cells in a porous collagen-glycosaminoglycan scaffold is affected by pore size and mechanical stimulation. J Mat Sci: Mat Med 19: 3455-3463.

Carter JD, Swearingen AB, Chaput CD, Rahm, MD (2009) Clinical and radiographic assessment of transforaminal lumbar interbody fusion using HEALOS collagen-hydroxyapatite sponge with Autologous bone marrow aspirate. Spine J 9: 434-438.

Dawson JI, Wahl DA, Lanham SA, Kanczler JM, Czernuszka JT, Oreffo ROC (2008) Development of specific collagen scaffolds to support the osteogenic and chondrogenic differentiation of human bone marrow stromal cells. Biomaterials 29: 3105-3116.

Desai BM (2007) Osteobiologics. Am J Orthop 36: 811.

Doillon CJ, Whyne CF, Brandwein S, Silver FH (1986) Collagen-based wound dressings: control of the pore structure and morphology. J Biomed Mater Res 20: 12191228.

Engler AJ, Richert L, Wong JY, Picart C, Discher DE (2004) Surface probe measurements of the elasticity of sectioned tissue, thin gels and polyelectrolyte multilayer films: correlations between substrate stiffness and cell adhesion. Surf Sci 570: 142-154.

Engler AJ, Sen S, Sweeney HL, Discher DE (2006) Matrix elasticity directs stem cell lineage specification. Cell 126: 677-689.

Gosain AK, Song L, Riordan P, Amarante MT, Nagy PG, Wilson CR, Toth JM, Ricci JL (2002) A 1-year study of osteoinduction in hydroxyapatite-derived biomaterials in an adult sheep model: Part 1. Plast Reconstr Surg 109: 619-630.

Greenwald AS, Boden SD, Goldberg VM, Khan Y, Laurencin CT, Rosier RN (2001) Bone-graft substitutes: facts, fictions, and applications J Bone Joint Surg Am. 83: 98-103.

Habibovic P, Yuan H, van den Doel M, Sees TM, van Blitterswijk CA, de Groot K (2006) Relevance of osteoinductive biomaterials in critical-sized orthotopic defect. J Orthop Res 24: 867-876.

Harley BA, Leung JH, Silva ECCM, Gibson LJ (2007) Mechanical characterization of collagenglycosaminoglycan scaffolds. Acta Biomater 3: 463-474.

Haugh MG, Jaasma MJ, O’Brien FJ (2009) The effect of dehydrothermal treatment on the mechanical and structural properties of collagen-GAG scaffolds. J Biomed Mater Res A 89: 363-369.

Hunziker EB (2002) Articular cartilage repair: basic science and clinical progress. A review of the current status and prospects. Osteoarthritis Cartilage 10: 432-463.

Hutmacher DW (2000) Scaffolds in tissue engineering bone and cartilage. Biomaterials 21: 2529-2543.

Ilan DI, Ladd AL (2003) Bone graft substitutes. Oper Techn Plas Recon Surg 9: 151-160.

Jaasma MJ, O’Brien FJ (2008) Mechanical stimulation of osteoblasts using steady and dynamic fluid flow. Tissue Eng Part A 14: 1213-1223.

Jungreuthmayer C, Donahue SW, Jaasma MJ, AlMunajjed AA, Zanghellini J, Kelly DJ, O’Brien FJ (2009) A comparative study of shear stresses in collagenglycosaminoglycan and calcium phosphate scaffolds in bone tissue-engineering bioreactors. Tissue Eng Part A. 15: $1141-1149$.

Karageorgiou V, Kaplan D (2005) Porosity of 3D biomaterial scaffolds and osteogenesis. Biomaterials 26: 5474-5491.

Kelly DJ, Prendergast PJ (2004) Effect of a degraded core on the mechanical behaviour of tissue-engineered cartilage constructs: a poro-elastic finite element analysis. Med Biol Eng Comp 42: 9-13.

Kennedy OD, Brennan O, Rackard SM, O’Brien FJ, Taylor D, Lee TC (2009) Variation of trabecular microarchitectural parameters in cranial, caudal and midvertebral regions of the ovine L3 vertebra. J Anat 214: 729-735.

Khatiwala CB, Peyton SR, Metzke M, Putnam AJ (2007) The regulation of osteogenesis by ECM rigidity in MC3T3-E1 cells requires MAPK activation. J Cell Physiol 211: 661-672.

Kikuchi M, Ikoma T, Itoh S, Matsumoto HN, Koyama Y, Takakuda K, Shinomiya K, Tanaka J (2004) Biomimetic 
synthesis of bone-like nanocomposites using the selforganization mechanism of hydroxyapatite and collagen. Compos Sci Technol 64: 819-825.

Laurencin C, Khan Y, El-Amin SF (2006) Bone graft substitutes. Expert Rev Med Dev 3: 49-57.

Le Nihouannen D, Daculsi G, Saffarzadeh A, Gauthier O, Delplace S, Pilet P, Layrolle P (2005) Ectopic bone formation by microporous calcium phosphate ceramic particles in sheep muscles. Bone 36:1086-1093.

Li J, Chen Y, Maka A, Tuan RS, Li L, Li Y (2010) A one-step method to fabricate PLLA scaffolds with deposition of bioactive hydroxyapatite and collagen using ice-based microporogens. Acta Biomater 6: 2013-2019.

Lyons F, Al-Munajjed A, Kieran S, Toner M, O'Brien FJ (2010) The healing of bony defects by cell-free collagenbased scaffolds compared to stem cell-seeded tissue engineered constructs. Biomaterials 2010 Sep 21 [Epub ahead of print] Doi:10.1016/j.biomaterials.2010.08.056.

Meikle MC (2007) On the transplantation, regeneration and induction of bone: the path to bone morphogenetic proteins and other skeletal growth factors. Surgeon 5: 23243.

Murphy CM, Haugh MG, O'Brien FJ (2010a) The effect of mean pore size on cell attachment, proliferation and migration in collagen glycosaminoglycan scaffolds for tissue engineering. Biomaterials 31: 461-466.

Murphy CM, O'Brien FJ (2010b) Understanding the effect of mean pore size on cell activity in collagenglycosaminoglycan scaffolds Cell Adh Migr 4: 377-381.

Mroz TE, Joyce MJ, Steinmetz MP, Lieberman IH, Wang JC (2008) Musculoskeletal allograft risks and recalls in the United States. J Am Acad Orthop Surg 16: 559-565.

O’Brien FJ, Harley BA, Yannas IV, Gibson L (2004) Influence of freezing rate on pore structure in freeze-dried collagen-GAG scaffolds. Biomaterials 25:1077-1086.

O’Brien FJ, Harley BA, Yannas IV, Gibson LJ (2005) The effect of pore size on cell adhesion in collagen-GAG scaffolds. Biomaterials 26: 433-441.

O’Brien FJ, Harley BA, Waller MA, Yannas IV, Gibson LJ, Prendergast PJ (2007a) The effect of pore size on permeability and cell attachment in collagen scaffolds for tissue engineering. Technol Health Care 15: 3-17.

O'Brien FJ, Plunkett N, Gleeson J (2007b) Granted US, EU GB \& JP PCT patent: WO2008096334A2. EP1964583 A collagen/hydroxyapatite composite scaffold, and process for the production thereof.

Partap S, Plunkett NA, O’Brien FJ (2010) Bioreactors in tissue engineering. In: Tissue Engineering (Lazinica A, ed), IN-TECH, Vienna (ISBN 978-953-7619-X-X). pp 323-336.

Plunkett NA, Partap S, O’Brien FJ (2010) Osteoblast response to rest periods during bioreactor culture of collagen-glycosaminoglycan scaffolds. Tissue Eng Part A 16: 943-951.

Ratcliffe A (2008) Translational approaches. In: Tissue Engineering and Regenerative Medicine. Artech House Publishers, Boston, pp 463-472.

Revell P, Braden M, Freeman M (1998) Review of the biological response to a novel bone cement containing poly(ethyl methacrylate) and n-butyl methacrylate. Biomaterials 19: 1579-1586.
Rowlands AS, George PA, Cooper-White JJ (2008) Directing osteogenic and myogenic differentiation of MSCs: interplay of stiffness and adhesive ligand presentation. Am J Physiol Cell Physiol 295: C1037-1044.

Roy TD, Simon JL, Ricci JL, Rekow ED, Thompson VP, Parsons JR (2003) Performance of degradable composite bone repair products made via threedimensional fabrication techniques. J Biomed Mater Res A 66: 283-291.

Sikavitsas VI, Bancroft GN, Lemoine JJ, Liebschner MA, Dauner M, Mikos AG (2005) Flow perfusion enhances the calcified matrix deposition of marrow stromal cells in biodegradable nonwoven fiber mesh scaffolds. Ann Biomed Eng 33: 63-70.

Spain TL, Agrawal CM, Athanasiou KA (1998) New technique to extend the useful life of a biodegradable cartilage implant. Tissue Eng 4: 343-352.

Supová M (2009) Problem of hydroxyapatite dispersion in polymer matrices: a review. J Mater Sci Mater Med 6:1201-1213.

Swetha M, Sahithi K, Moorthi A, Srinivasan N, Ramasamy K, Selvamurugan N (2010) Biocomposites containing natural polymers and hydroxyapatite for bone tissue engineering. Int J Biol Macromol 47 :1-4.

Takahashi Y, Tabata Y (2004) Effect of the fiber diameter and porosity of non-woven PET fabrics on the osteogenic differentiation of mesenchymal stem cells. J Biomater Sci Polym 15: 41-57.

ter Brugge PJ, Wolke JG, Jansen JA (2002) Effect of calcium phosphate coating crystallinity and implant surface roughness on differentiation of rat bone marrow cells. $\mathrm{J}$ Biomed Mater Res 60:70-78.

Tierney CM, Haugh MG, Liedl J, Mulcahy F, Hayes B, O'Brien FJ (2009a) The effects of collagen concentration and crosslink density on the biological, structural and mechanical properties of collagen-GAG scaffolds for bone tissue engineering. J Mech Behav Biomed Mater 2: 202-209.

Tierney CM, Jaasma MJ, O’Brien F (2009b) Osteoblast activity on collagen-GAG scaffolds is affected by collagen and GAG concentrations. J Biomed Mater Res A 91: 92101.

Toolan BC (2006) Current concepts review: Orthobiologics. Foot Ankle Int 27: 561-566.

Venugopal J, Low S, Choon AT, Sampath Kumar TS, Ramakrishna S (2008) Mineralization of osteoblasts with electrospun collagen/hydroxyapatite nanofibers. J Mater Sci Mater Med 19: 2039-2046.

Wahl DA, Czernuszka JT (2006) Collagenhydroxyapatite composites for hard tissue repair. Eur Cell Mater 11: 43-56.

Woodfield TB, Bezemer JM, Pieper JS, van Blitterswijk CA, Riesle J (2002) Scaffolds for tissue engineering of cartilage. Crit. Rev. Eukaryot Gene Expr 12: 209-236.

Yoshida T, Kikuchi M, Koyama Y, Takakuda K (2010) Osteogenic activity of MG63 cells on bone-like hydroxyapatite/collagen nanocomposite sponges. J Mater Sci: Mater Med 21:1263-1272.

Yuan H, Van Den Doel M, Li S, Van Blitterswijk CA, De Groot K, De Bruijn JD (2002) Comparison of the osteoinductive potential of two calcium phosphate 
ceramics implanted intramuscularly in goats. J Mater Sci Mater Med 13: 1271-1275.

Zhang L, Tang P, Xu M, Zhang W, Chai W, Wang Y (2010a) Effects of crystalline phase on the biological properties of collagen-hydroxyapatite composites. Acta Biomater 6: 2189-2199.

Zhang L, Tang P, Zhang W, Xu M, Wang Y (2010b) Effect of chitosan as a dispersant on collagenhydroxyapatite composite matrices. Tissue Eng Part C Methods 16: 71-79.

$\mathrm{Xu}$ Z, Neoh KG, Kishen A (2010) A biomimetic strategy to form calcium phosphate crystals on type I collagen substrate. Mater Sci Eng C 30: 822-826.

\section{Discussion with Reviewers}

Reviewer I: At the end of the first paragraph of the Discussion, the authors state that "the high porosity, combined with increased mechanical properties and improved permeability make it an ideal template to promote cell ingrowth and subsequent vascularisation". The authors do not mention pore size as playing a role? In addition, did the authors see vascularisation in their in vivo study?

Authors: We agree with the reviewer's comment that pore size plays a role in cell ingrowth and subsequent vascularisation. (The reviewer may be aware that our group has published extensively on the role of scaffold pore size on cell behaviour e.g.: O'Brien et al., 2005, 2007a; Byrne et al., 2008; Murphy et al., 2010a,b). However, the scaffolds investigated in this study have similar pore sizes so pore size did not affect the results obtained i.e. any variability between groups was not as a result of scaffold pore size (see discussion below). Regarding vascularisation of the scaffolds, the authors did not specifically quantify vascularisation as part of this study. Ongoing work within our laboratory is focussed on a more extensive in vivo study (in rabbit long bones) than that shown in this manuscript, quantitative histomorphometry will be used to quantify to both osteogenesis and angiogenesis. Unfortunately, such an analysis was beyond the scope of the current study due to ethical approval being granted only for a preliminary trial.

Reviewer I: Did the authors look at the microstructure of the different scaffolds after production? For example does the mineral particle size change or alter at all after the invitro assay? Porosity and permeability give some information about the microstructure, but it is known that pore size also plays a role. What is the pore size of the different scaffolds?

Authors: The authors have examined the microstructure of the different scaffolds after their production. The four scaffold groups investigated as part of the study (namely collagen, $50 \mathrm{wt} \% \mathrm{HA}, 100 \mathrm{wt} \% \mathrm{HA}$ and $200 \mathrm{wt} \% \mathrm{HA}$ groups) have similar pore sizes, homogeneity and pore distribution. This allowed the authors to exclude pore size as a variable affecting the results obtained. Hydroxyapatite particle distribution was assessed using Energy Dispersive $\mathrm{X}$-Ray analysis and microCT and particles were found to be homogenously distributed in all three CHA scaffold groups. Particle size was assessed qualitatively using SEM and was found to be unaffected by the fabrication process. Average scaffold pore size was $120 \mu \mathrm{m}$.

Reviewer I: It is now well known (from Engler et al., 2004; Engler et al., 2006, text references) that stiffness controls cell response; however substrate chemistry also plays a role. Changing the composition in terms of the $\mathrm{HA} /$ collagen ratio also changes the chemistry, could the authors comment on the relative importance of these two features? Can they be separated?

Authors: The authors agree with the reviewer's comment that changing the composition of the scaffolds in terms of $\mathrm{HA} /$ collagen ratio might change the chemistry of the cellular interactions within the CHA scaffolds. The results suggest that increased permeability as a result of improved stiffness increases cell infiltration and thus cell number within the scaffold (Fig. 4), while the increased levels of the osteoinductive HA phase (predominantly chemical effect), leads to the overall increased levels of mineralisation (Fig. 5 and Fig. 6). However, it is difficult to directly uncouple the effects of chemical and mechanical interaction between the scaffold and the cells. It is likely that it is a combined effect that leads to the improved cellular responses seen.

Reviewer I: Macroscopic compression tests were made to calculate stiffness. This measure is of course important to predict the stability of the scaffold, however is not necessarily the value of stiffness the cells will feel. Can the authors comment on this?

Authors: Recent studies have investigated the bulk and localised mechanical properties of collagen-based scaffolds manufactured using an identical fabrication process to the one employed throughout this study (Harley et al., 2007). Harley and colleagues used a combination of empirical and theoretical models to investigate differences in bulk and local stiffness values for highly porous collagen-based scaffolds and found that when hydrated, strut stiffness was approximately four orders of magnitude greater than the stiffness values measured using standard mechanical testing of bulk specimens. The nature of high porosity structures means that their bulk mechanical properties are dramatically different to the mechanical properties of the individual struts within the open foam network. As a result, the substrate stiffness that a cell feels while attached to one or multiple struts within the porous scaffold can be significantly higher than that predicted by bulk assessment of the material. Due to the relatively small pore size in the scaffolds produced using the lyophilisation technique used in this study, the stiffness the cell's sense will be governed by a combination of both bulk and tissue modulus because we know that $75 \%$ of cells will bridge pores (Jungreuthmayer et al., 2009, text reference) and thus they are not seeing a flat planar surface. Using a cellular solids model, such as the Gibson Ashby approach, it was estimated that the substrate stiffness experienced by a cell attached within the pores of the CHA scaffold would be of the order of approximately 50 to $100 \mathrm{MPa}$. 
Reviewer II: Why is there a reduction in the number of cells at 28 days in the collagen scaffolds (especially as collagen scaffold is considered 'gold standard'? Or is this change not significant?

Authors: The decrease in cell number on the collagen control scaffolds was not statistically significant after 28 days. However, the trend of increasing cell number seen in all CHA scaffolds (and statistically significant in the 50 wt $\%$ and $100 \mathrm{wt} \%$ HA scaffolds) was interesting with respect to previous studies within our group that have looked at cell attachment. There are a number of factors that can affect cell attachment, most notably scaffold pore size for example (Jungreuthmayer et al., 2009, text reference) but the scaffolds investigated throughout this study have similar pore sizes. Interestingly, only the collagen control scaffolds showed a net decrease in cell number after 28 days in culture and we hypothesise that this may be due to the increased permeability seen in the CHA scaffolds. 